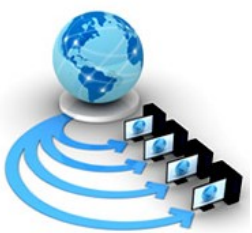

Volume 9, No. 6, November-December 2018

\title{
PREDICTIVE ANALYTICS IMPLEMENTING GENETIC ALGORITHM ON CLASS SCHEDULING SYSTEM
}

\author{
Louie F. Agustin*, John Kevin A. Losito, Analyn R. Mendoza and Ashley T. Factoriza \\ College of Computer Studies, Trimex Colleges, \\ Biñan, Laguna, Philippines
}

\begin{abstract}
Although still considered as an infant educational institution, Trimex Colleges has already made a name as a school in Laguna, Philippines. Its student population has ballooned that it is now faced with the predicament of addressing concerns like course-loading of faculty according to their time and day preferences and most especially accommodating students who thirsts for academic excellence on its available classrooms. The study entitled "Predictive Analytics Implementing Genetic Algorithm on Class Scheduling System" was made on purpose to be able to address all these concerns. The system could easily generate class schedules and faculty course loading at a minimal time. It can also predict whether or not a course will be divided into sections based on the data acquired from the previous terms. The results of the software evaluation proved that the system met the objectives of the study and can be of great help for the school.
\end{abstract}

Keywords: Algorithm; Predictive Analytics; Implementing Genetic; Class Scheduling; Virtual

\section{INTRODUCTION}

Results of a string of interviews conducted by the proponents in at least four schools reveal that persons in charge of schedules share the same sentiments, that is, personal preferences of part-time teachers and room shortages. Worthy of note, though that they differ in their suggestions as to how a scheduler be called. Names/Titles like Master Scheduler, Program Scheduler, Senior Faculty, Assistant Dean, Assignor of Schedules, Academic Assistant, and Program Chair were suggested.

For purposes of this study, he should be referred to here as Program Scheduler. Noticeable also that in Universities, the task is assigned to Deans of the different Departments.

However, the time has an answer for almost everything technology.

Today, almost everything is dependent on technology, since the same could save precious time, effort, including economic considerations: more, technology's capability as an instrument of nation-building. Proponents humbly made this study, not only to unburden person in charge of the schedules but also to give him a breather.

The study entitled "Predictive Analytics Implementing Genetic Algorithm on Class Scheduling System" was made on purpose to be able to address all these concerns.

The system could easily generate class schedules and faculty course loading at a minimal time. It can also predict whether or not a course will be divided into sections based on the data acquired from the previous terms. The results of the software evaluation proved that the system met the objectives of the study and can be of great help for the school.

Last and more importantly, this study is proponents' gesture of gratitude to their alma mater, to which they owe much of their knowledge.

\subsection{DESIGN OF THE STUDY}

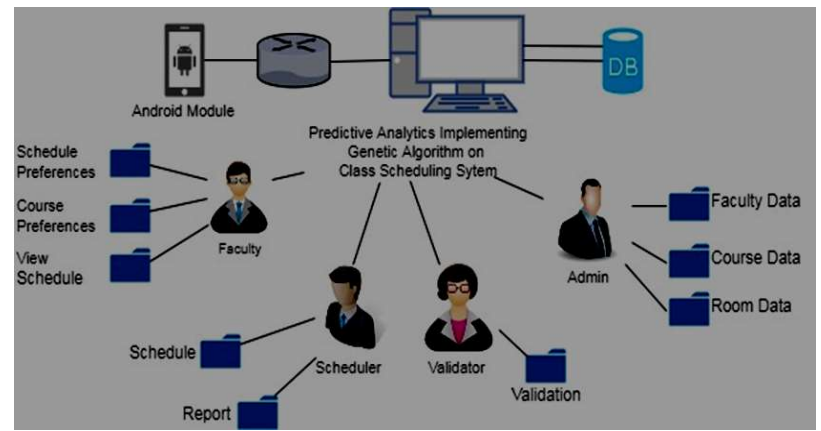

Figure 1 System Architecture

The figure demonstrates the distinctive parts of the Class Scheduling System Implementing Predictive Analytics Using Genetic Algorithm. There will be clients like the Administrator, who regulate clients account, the age of calendar, the room the board, and deal with the reports.

\subsection{NETWORK DESIGN INFRASTRUCTURE}

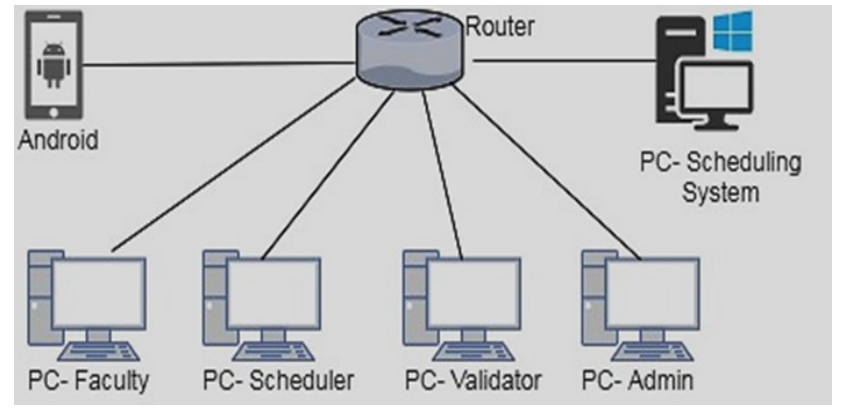

Figure 2 Network Design Infrastructure 


\subsection{DATABASE SCHEMA}

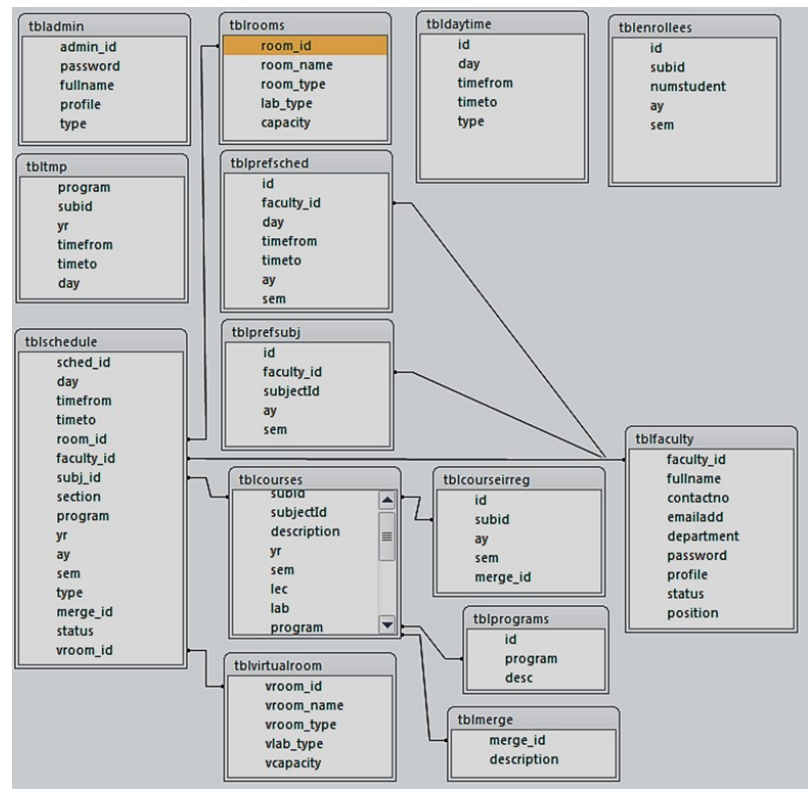

Figure 3 Database Schema

The figure above demonstrates that the database has an element relationship that can be made with the tables. It empowers a common database to store a large measure of information productively and adequately recover chosen information.

\section{USE CASE DIAGRAM}

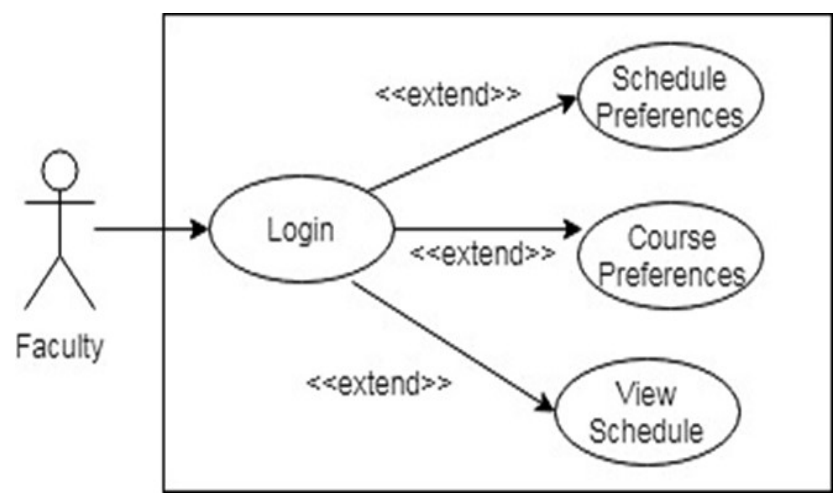

\section{Figure 4 Faculty Module}

The figure indicates how a workforce can acknowledge the accompanying module: login, plan inclinations, course inclinations, and a survey of the calendar.

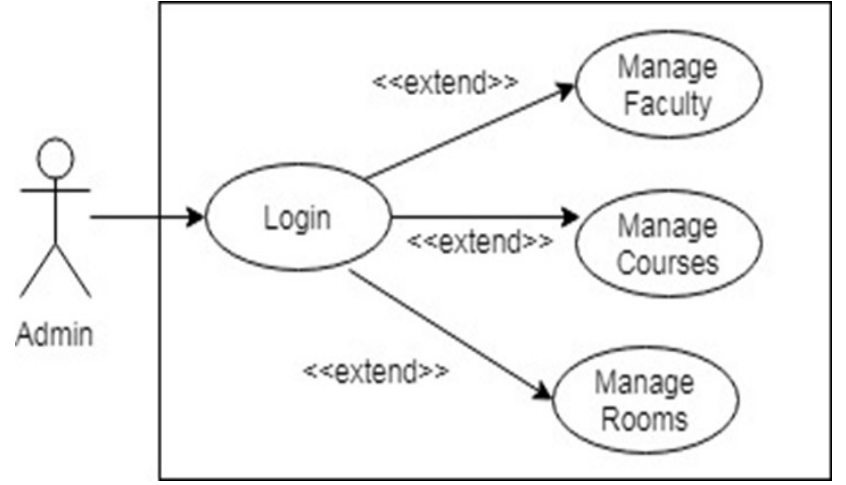

Figure 5 Admin Module

The figure indicates how a manager can acknowledge the accompanying module: login, oversee personnel, oversee courses, and oversee rooms.

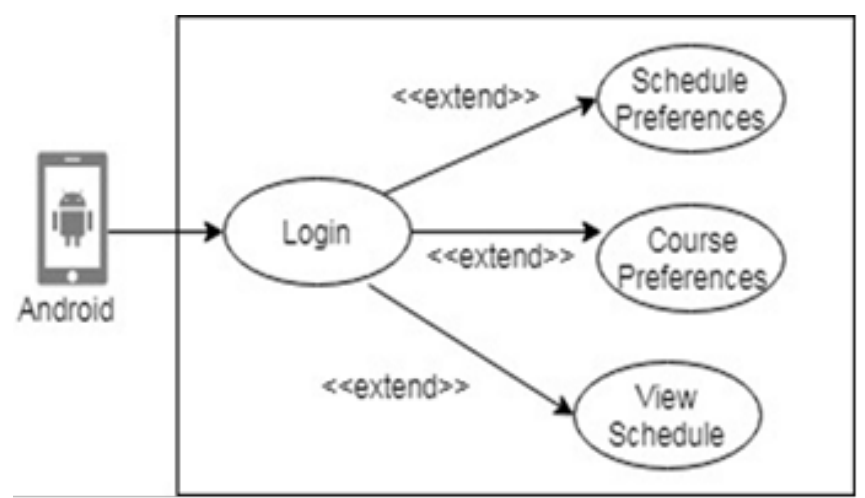

Figure 6 Android Module

The figure demonstrates the modules of the android application.

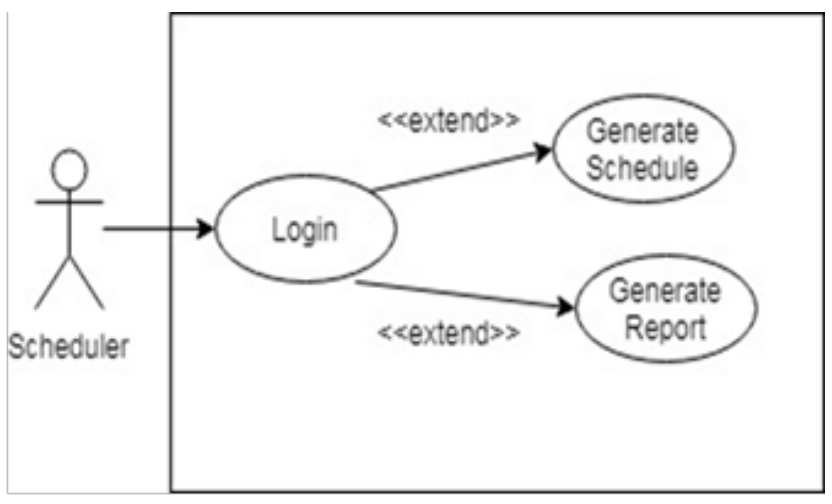

Figure 7 Android Module

The figure demonstrates how a scheduler can acknowledge the accompanying module: login, the age of timetables, and reports. 


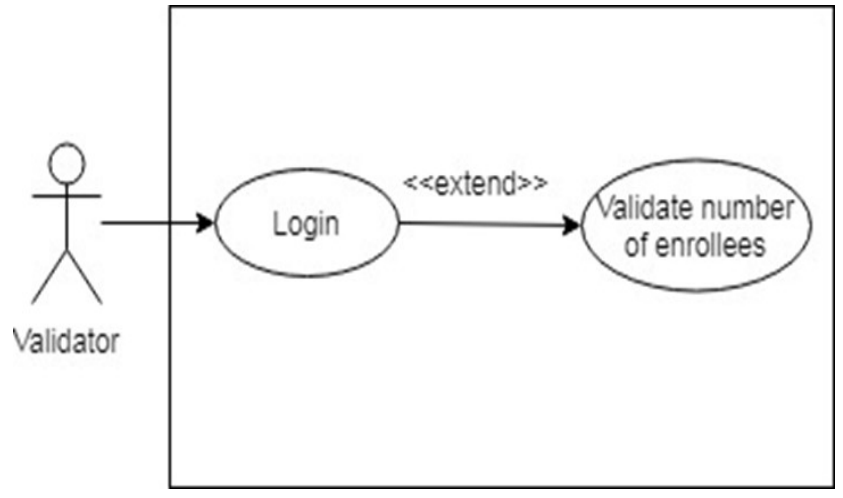

Figure 8 Validator Module

The figure demonstrates how a validator approves some understudies.

\subsection{FLOW CHART}

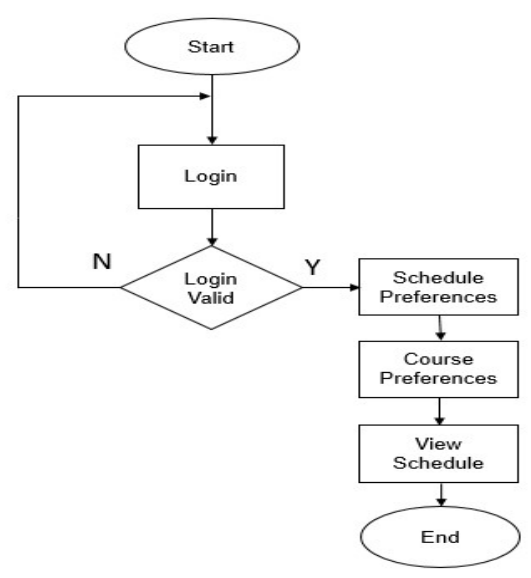

Figure 9 Faculty

Staff will $\log$ in to System after fruitful login; the workforce can include time/day and course inclinations, and view plan.

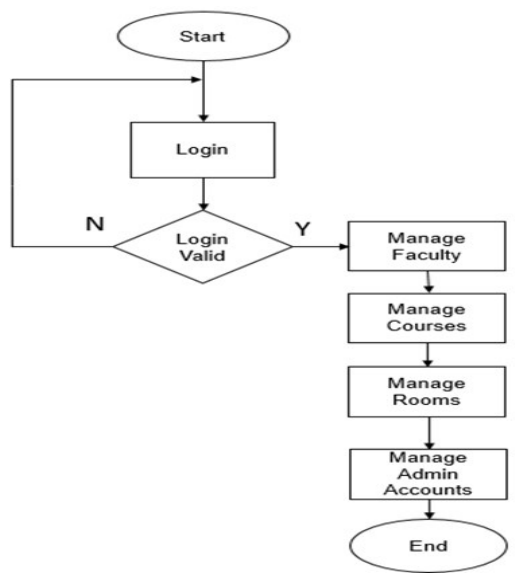

Figure 10 Admin

The super administrator can oversee workforce information/data, courses, rooms, and administrator accounts.

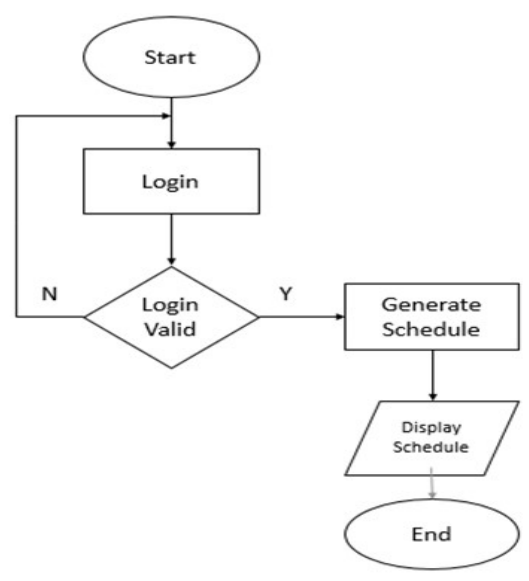

Figure 11 Scheduler

The client can produce a calendar and show reports.

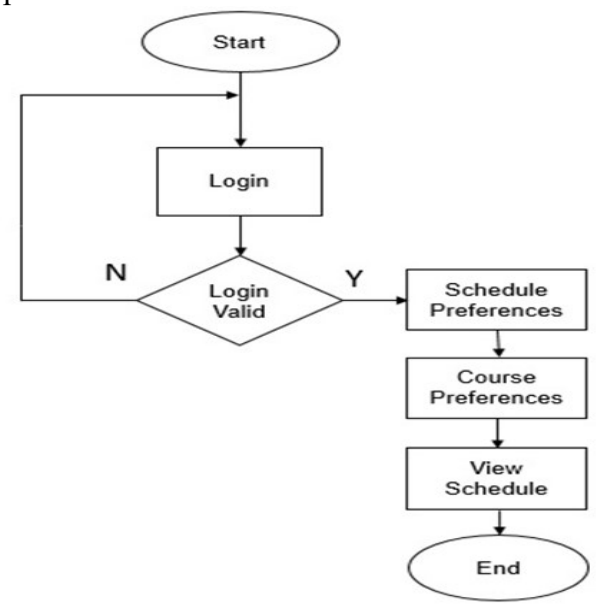

Figure 12 Android

The workforce will $\log$ in to System utilizing the Android application, after valid login, personnel can enter time/day and course inclinations, and view plan.

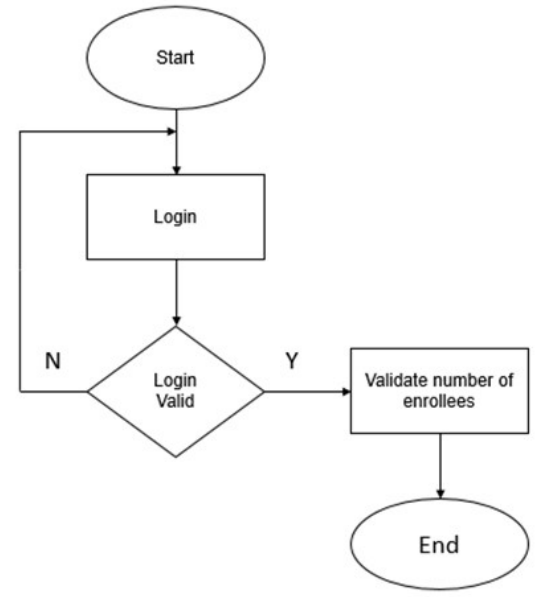

Figure 13 Validator

The client refreshes the quantity of understudies enlisted in each course. 


\section{LITERATURE SURVEY}

As per the Authors, to build up this Predictive Analytics Implementing Genetic Algorithm on Class Scheduling System [1] that will anticipate if an explicit subject should be partitioned into areas with the goal that each classroom won't surpass its most extreme limit.

As indicated by the Authors, to build up this examination Predictive Analytics Implementing Genetic Algorithm on Class Scheduling System [2] that will execute a hereditary calculation to produce a calendar as indicated by the resources favored subjects to educate and time accessibility.

As per the Authors, to make the framework [3] that will demonstrate a virtual classroom if there are no more rooms accessible.

As per the Authors, to make an android application in the Predictive Analytics Implementing Genetic Algorithm on Class Scheduling System [4] that will be utilized by the employees to see their calendar.

\section{RESULT AND DISCUSSION}

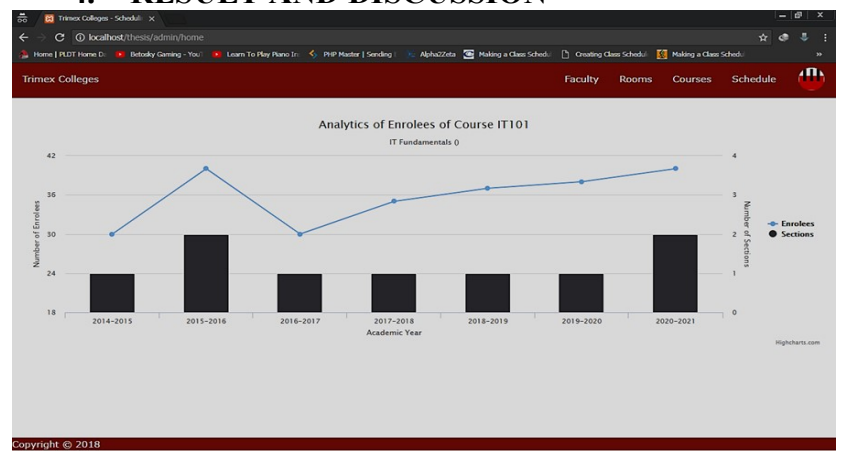

Figure 14 Analytics

The figure above shows analytics of the enrollee data of a specific course and its prediction for the next years, including the number of sections of the said course.

\begin{tabular}{|c|c|c|c|}
\hline \multicolumn{4}{|l|}{ Generate schedule } \\
\hline \multirow{2}{*}{ Schedule of School } & Room Name & Room Type & Lab Type \\
\hline & VRoom-1 & lec & na \\
\hline \multirow{2}{*}{ Faculty Load } & VRoom-2 & lec & na \\
\hline & VRoom-3 & lec & na \\
\hline \multirow{2}{*}{ Program Schedule } & VRoom-4 & lab & phy \\
\hline & VRoom-5 & lec & na \\
\hline \multirow[b]{2}{*}{ No Classroom } & VRoom-6 & lec & na \\
\hline & VRoom-7 & lec & na \\
\hline \multirow{3}{*}{ Virtual Classroom } & VRoom-8 & lec & na \\
\hline & VRoom-9 & lec & na \\
\hline & VRoom-10 & lec & na \\
\hline
\end{tabular}

\section{Figure 15 Virtual Classroom}

The figure above shows the classrooms (virtual) that were created by the system due to room shortage.

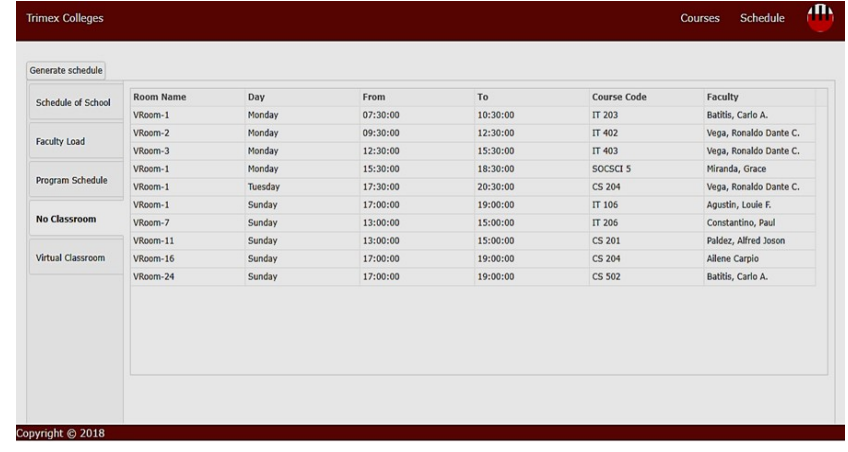

Figure 16 No Classrooms

The figure above shows the schedule of courses which used the virtual classroom.

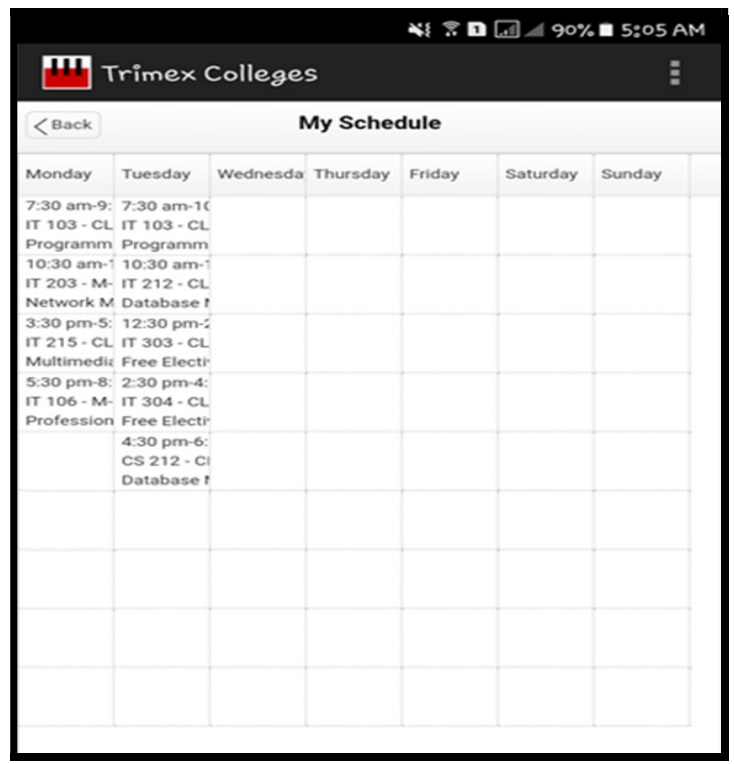

Figure 17 Android application

To create an android application that will be used by faculty members to view their schedule.

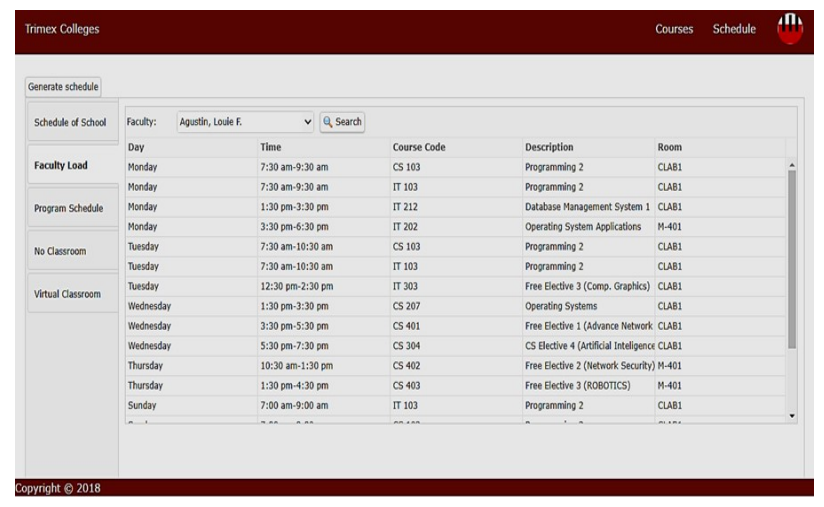

\section{Figure 18 Android application}

The figure above shows the generated schedule of a faculty based on his time and day availability which used the genetic algorithm. 


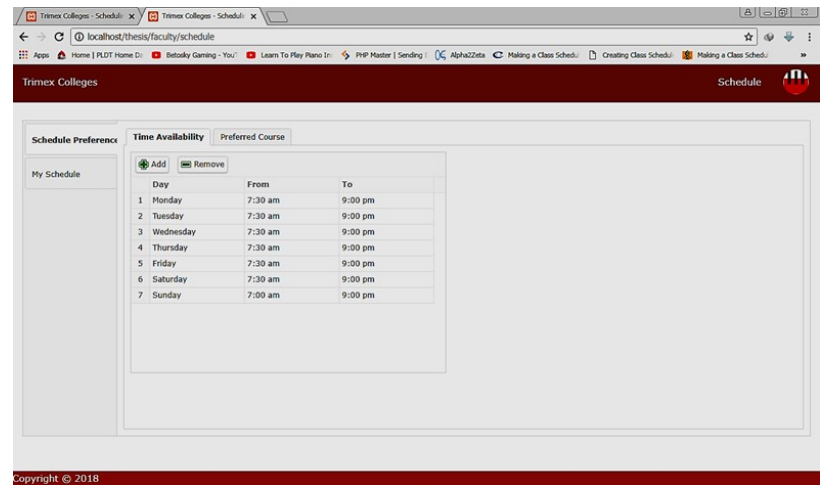

Figure 19 Android application

The figure above shows the time and day availability of an instructor.

\section{SUMMARY}

Room assignments and personnel stacking are the most troublesome undertaking of the program schedule since he needs to consider the time accessibility of educators and room assignments to stay away from clashes.

This investigation will offer an approach to simple age of class calendars and staff stacking at a negligible time. It likewise predicts regardless of whether a course will be partitioned into areas dependent on the information gained from the past terms.

\subsection{CONCLUSION}

Having completed the formative periods of the investigation and classified the consequences of the assessment, the advocates presumed that the utilization of prescient examination would be valuable to foresee the number of understudies in a course and to part it into segments if necessary to help limit classroom over-burden. If classrooms are completely possessed, and there are still courses without room task, virtual classroom will be introduced. Employees may use android application wherein they could propose their time, directions, and day inclinations. They may likewise see their calendar. Finally, Genetic Algorithm is the most appropriate calculation to create plans since the procedure and information utilized by Trimex Colleges in making class plans fit the criteria, portrayal, and method of the said calculation.

\subsection{RECOMMENDATION}

The advocates firmly prescribe to the future specialists that the framework is transferred to the web to make it on the internet, and incorporated to the school enrolment. Additionally, a module ought to be included that will enable the understudies to see their calendar.

On the off chance that the future analysts wish to make this examination a reference and guide for a comparable framework, the equivalent ought to be updated, so as not to raise worry from the creators.

\section{REFERENCES}

[1] Jeralyn M. Gamale, Edward C. Anuta, Zina D. Sayson "Automated class scheduling system," Study held in 2012 - 2013, Bohol Island State University.

[2] Dr. Dibon "Online-Based Instructors Scheduling System," 2010.

[3] Prabhat Shrivastava, S.L. Dhingra,P.J. Gundaliya "Application Of Genetic Algorithm For Scheduling And Schedule Coordination Problems," Journal of Advanced Transportation, Vol. 36 No. I,pp. 23-41. 